\title{
A new species of Copepoda Harpacticoida, Xylora calyptogenae spec. n., with a carnivorous life-style from a hydrothermally active submarine volcano in the New Ireland Fore-Arc system (Papua New Guinea) with notes on the systematics of the Donsiellinae Lang, 1948
}

Received: 27 April 2004/ Revised: 20 March 2006/ Accepted: 22 March 2006/Published online: 26 April 2006 (C) Springer-Verlag and AWI 2006

\begin{abstract}
A new species of harpacticoid copepods, Xylora calyptogenae spec. n., from Edison Seamount, a hydrothermally active submarine volcano in the New Ireland Fore-Arc system (Papua New Guinea) is described. The new species belongs to the Donsiellinae Lang, 1944, a highly specialised taxon, the members of which have previously been encountered only in association with decaying wood and/or wood-boring isopods. A closer relationship of the Donsiellinae with the Pseudotachidiidae Lang, 1936, can be stated on the basis of characteristics concerning the setation and/or segmentation of A1, A2, Mxl, Mxp, the shape of the female P5, anal somite, sexual dimorphisms on P2 and P3 and missing caudal seta I. Within the Pseudotachidiidae, the Donsiellinae again can be well characterized, e.g. by the setation and segmentation of $\mathrm{A} 2, \mathrm{Mxl}$, swimming-legs, the shape of P1, female P5, male P2, sexual dimorphism and male P5. The Donsiellinae share some apomorphies with the pseudotachidiid subtaxon Paranannopinae Por, 1986: setation/segmentation of $\mathrm{Mx}, \mathrm{P} 1, \mathrm{~A} 1$. X. calyptogenae spec. $\mathrm{n}$. is more closely related to Xylora bathyalis Hicks 1988 living in the deep sea wood substrata in New Zealand waters. Some traits of the evolutionary history of the Donsiellinae become evident, probably starting from the more primitive deep sea taxa $X$.calyptogenae spec. $\mathrm{n}$., which lives in the hydrothermal seafloor in the absence of decaying wood, and $X$. bathyalis, which is found in decaying wood but not necessarily associated with the wood-boring isopod Limnoria Leach, 1814, towards the
\end{abstract}

Communicated by H.-D. Franke

E. Willen

Fakultät V, Institut für Biologie und Umweltwissenschaften, Zoosystematik und Morphologie, Carl v. Ossietzky Universität Oldenburg, 26111 Oldenburg, Germany

E-mail: cybertravel@web.de

Tel.: +49-441-7983611 more advanced genera such as Donsiella Stephensen, 1936, which invades shallow waters and, further, clings to Limnoria, forming a close and, for the copepod, probably obligatory association. The specialised mouthparts of $X$. calyptogenae spec. $\mathrm{n}$. seem to facilitate the grabbing and fixing of larger and/or active food items. This is confirmed by the presence of a large prey organism, presumably a copepod, consumed either alive or dead, in the gut of one of the available specimens. This morphology of the mouthparts is also shared by the closely related $X$. bathyalis.

Keywords Hydrothermal vent - New Ireland Fore-Arc system · Copepoda Harpacticoida · Donsiellinae · Carnivorous life-style

\section{Introduction}

During a cruise of RV Sonne in 1998 (So-133), various sites of submarine volcanoes of the New Ireland ForeArc system have been sampled. Specimens of the species Xylora calyptogenae spec. $\mathrm{n}$., described herein, were present in one of the two samples from the hydrothermally active Edison Seamount in the Southern Clam field (station 33) but were absent in the samples from other sites. This species was encountered together with a species of Pseudobradya Sars, 1904 (Ectinosomatidae Sars, 1903) and an unknown species of Pseudotachidiidae Lang, 1936 (with several individuals each) and with one specimen of Argestidae Por, 1986. However, the far most abundant species at this location, represented by adults of both sexes and in the late copepodid stages was Stenhelia gundulae Willen, 2003. The samples from Edison Seamount (stations 10 and 33) were taken by GTVA-grabs and contained basaltic pepperite with numerous small xenoliths, as well as a great number of vesicomyid clams and a richly associated fauna, 
indicating hydrothermal activity. The recovered sediment had a comparably coarse-grained consistency.

Hydrothermal vents are extreme environments, containing a physiologically and morphologically well developed macrofauna, e.g., vestimentiferans, vesicomyid clams, bathymodiolid mussels, alvinellid polychaetes, alvinocarid shrimps (compare Tunnicliffe et al. 1998). The meiofauna such as copepods or nematodes of hydrothermal vents is much less known. The question whether this fauna is also highly specialised, cannot be answered yet. For instance, the Dirivultidae Humes and Dojiri, 1980 (Copepoda, Siphonostomatoida), which represent $10 \%$ of the vent copepods known worldwide, are reported from vents and seeps only. On the other hand, a different impression is given by the free-living nematodes from hydrothermal deep-sea sediments in the North Fiji Basin, where the genus composition does not deviate greatly from control areas in adjacent oxic deepsea sediments (Vanreusel et al. 1997). X. calyptogenae spec. n. again belongs to the highly specialised Donsiellinae, the species which have previously been encountered only in association with decaying wood and/or wood-boring isopods, and thus seem to be adapted to an unstable and sporadic habitat. The systematic position of the new species, the systematics of the Donsiellinae and some ecological aspects concerning their habitat will be discussed. Morphological pecularities of the new species will be compared with the data from the literature about the feeding behaviour of harpacticoids.

\section{Materials and methods}

Holotypes and allotypes were preserved in 5\% buffered formalin and subsequently transferred to glycerine. Drawings were made with the aid of a camera lucida on a Leica Diaplan microscope, equipped with UCA condenser, IC prism and doubler $\times 1.5$. The dissected parts were mounted on several slides. The terminology has been adopted from Lang $(1948,1965)$ except for the segmental composition of mandible, maxilliped and the numbering of the furcal setae, in which cases Huys and Boxshall (1991) have been followed. Abbreviations used in the text are: Aes, aesthetasc; exp, exopodite; enp, endopodite; enp1, first segment of endopodite; Md, mandible; Mxl, maxillula; Mx, maxilla; Mxp, maxilliped; P1-P6, swimming legs 1-6; benp, baseoendopodite of P5; Ro, rostrum; Ceph, Cephalothorax.

The term "basic pattern" is used in the sense of "Grundmuster" or "groundpattern" according to Ax (1984).

\section{Material examined}

Xylora calyptogenae spec. n. 1 female holotype, paratypes: 1 female specimen dissected, 7 more female specimens. Cruise SO-133 of RV Sonne south of Lihir Island,
Papua New Guinea, July 20-August 3, 1998. Type locality: Edison Seamount, Station 33 GTVA, Southern Clam field, $3^{\circ} 19.097^{\prime} \mathrm{S}, 152^{\circ} 34.864^{\prime} \mathrm{E}$ to $3^{\circ} 19.041^{\prime} \mathrm{S}$, $152^{\circ} 34.854 \mathrm{E}$, depth $1446 \mathrm{~m}$. The samples were taken by TV-grabs, together with macrofauna in a sediment matrix. The type material is stored in the copepod collection of the AG Zoosystematik und Morphologie at the C.v.O. Universität Oldenburg, Germany. Catalogue No.: holotype: UNIOL 2001.040.1-12, three paratype specimens: UNIOL 2001.041, UNIOL 2001.042, UNIOL 2001.043 .

\section{Results}

Xylora calyptogenae spec. $\mathrm{n}$.

\section{Description of female holotype}

Body length (rostrum tip to end of caudal rami): $600 \mu \mathrm{m}$. Maximum body width (measured at the rear margin of cephalothorax): $200 \mu \mathrm{m}$.

Rostrum (Figs. 1, 3) ventrally deflected, margins of hyaline appearance, demarcated from cephalothorax, broader than long, rounded, with originally two pairs of sensilla on dorsal surface and one pair apically, however, only two surface sensillae are actually present in the holotype specimen, the missing sensillae indicated by holes on the rostral surface. In the dissected paratype specimen only the two distal pairs of sensilla are present.

Labrum (Fig. 9). Small, smooth on the anterior surface, posterior completely covered with spinules, with two spinulose projections on lateral margins.

Body (Figs. 1, 2). Distinct separation between broad prosome and smaller urosome. Cephalothorax slightly longer than broad, cephalic shield with pattern of sensilla and pores. Posterior margin of each body somite (excl. penultimate somite) with sensilla, which are more numerous on the thoracic somites; last thoracal (P6 bearing somite) and abdominal somites laterally with spinule rows. Hyaline frills smooth; genital double somite (free somites 5 and 6 ) fused dorsally but ventrally separated by sclerotised ridge, genital field as in Fig. 2a; large copulatory pore Y-shaped, surrounded by sclerotised plate, $\mathrm{P} 6$ bearing one outer bipinnate and two inner minute setae, urosome (Fig. 2a) ventrally smooth, except for the spinules fringing posterior margins of postgenital and subsequent abdominal somites (except anal somite); anal somite completely divided, dorsally covered by pseudoperculum, anal operculum absent.

Caudal rami (Figs. 1, 2) app. 1.25 times as long as broad, all furcal setae located terminally, I missing, II and III at outer distal edge, IV and V well developed, VI slender, at inner edge, VII triarticulated, subterminally near inner margin on dorsal surface.

Antennule (Figs. 1, 2, 3) with seven short segments, all setae smooth and slender. Armature: I(1); II(10); III(8); IV(6 + aes); V(5); VI(3); VII(7 + aes). 


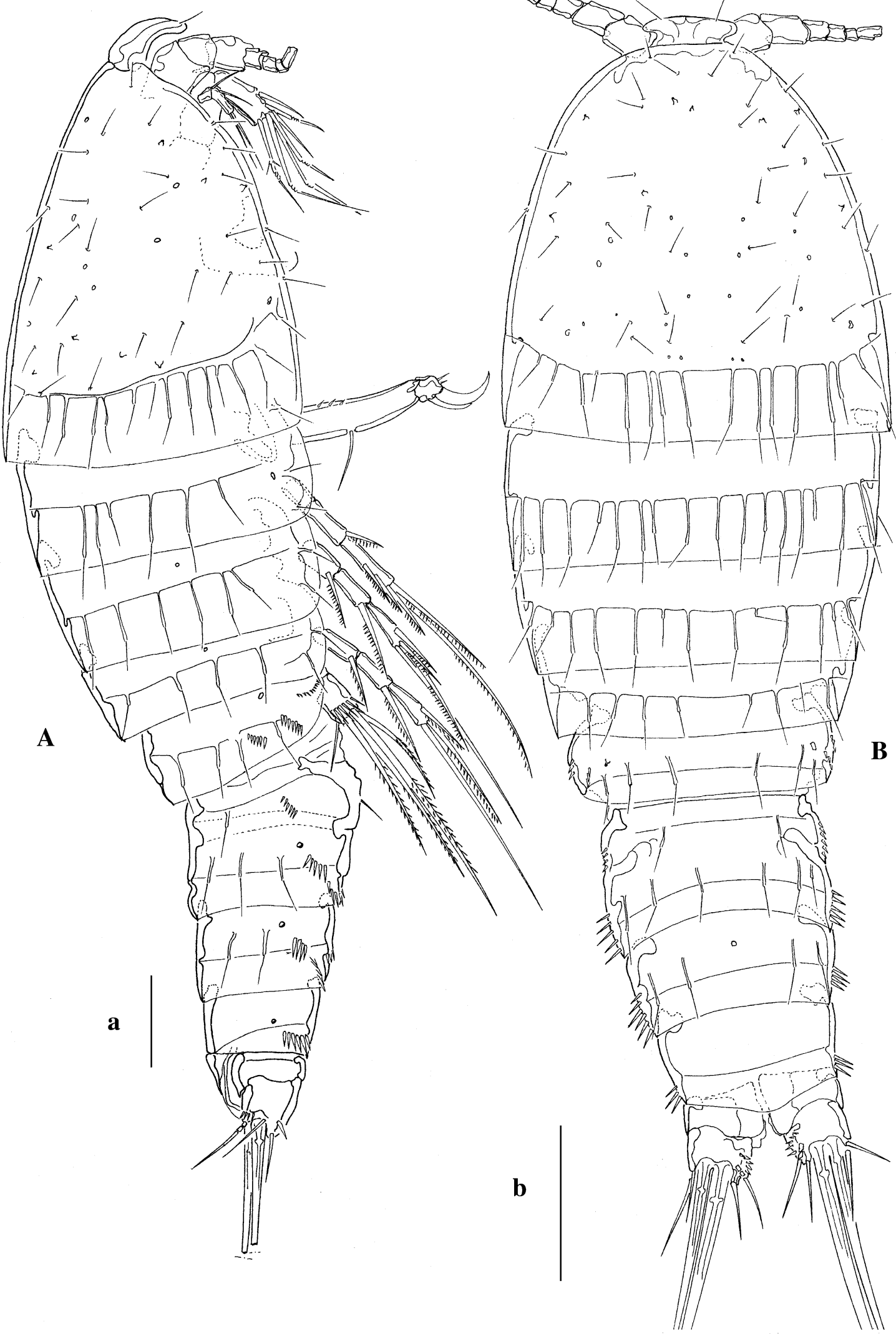

Fig. 1 Xylora calyptogenae gen. n., spec. n., female holotype. $A$ habitus in lateral view, $a$ scale bar $=50 \mu \mathrm{m} ; B$ : habitus in dorsal view, $b$ scale bar $=80 \mu \mathrm{m}$ 


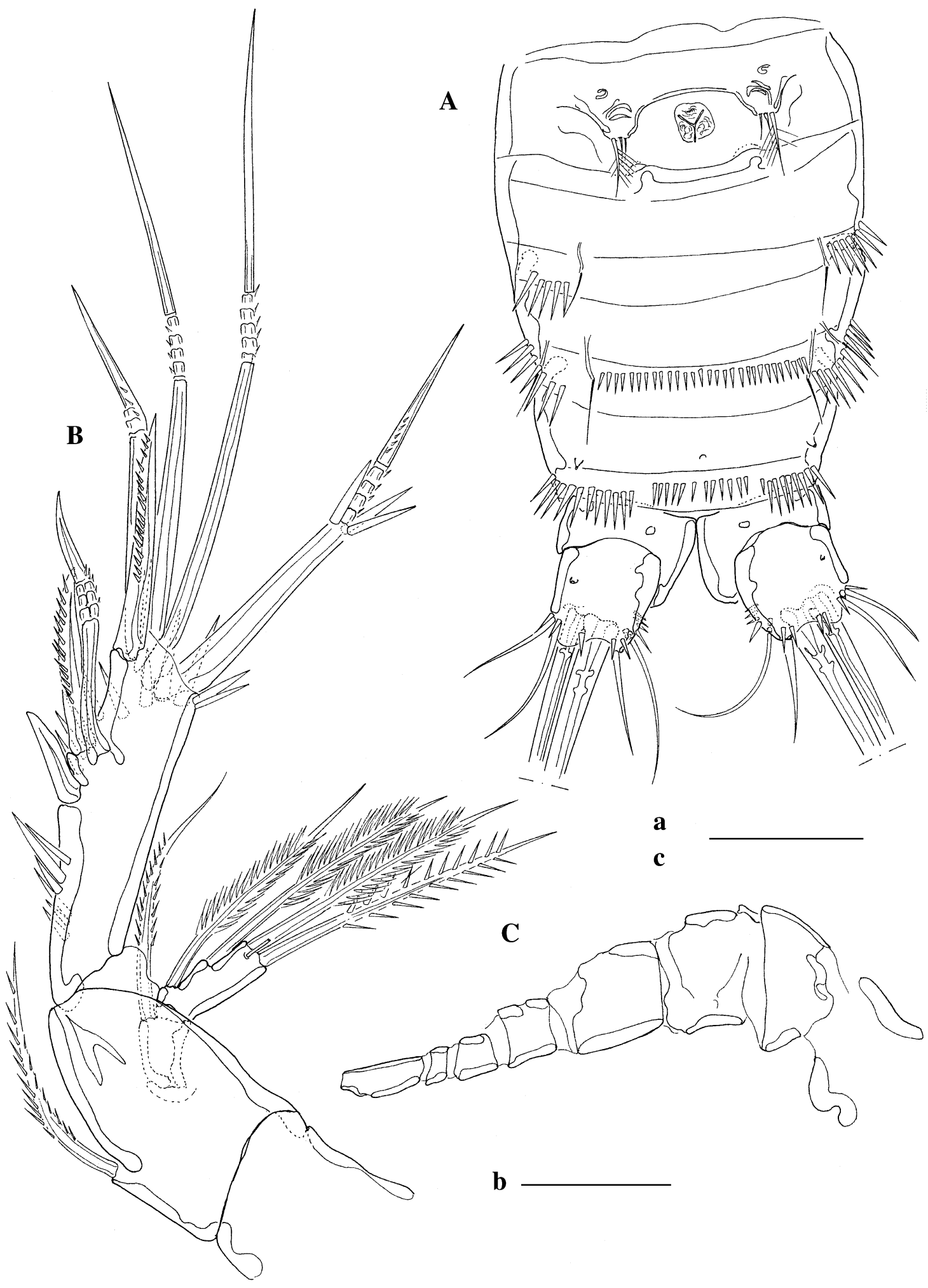

Fig. 2 Xylora calyptogenae gen. n., spec. n., female holotype. $A$ urosome and genital field in ventral view, $a$ scale bar $=50 \mu$; $B$ Antenna, $b$ scale bar $=20 \mu \mathrm{m}$; $C$ Antennule, $c$ scale bar $=30 \mu \mathrm{m}$

Antenna (Fig. 2). Allobasis with abexopodal pinnate seta in proximal half; exp two-segmented, with $1-2+2$ setae and apical tube pore; enp with proximal and subapical spinule rows; subapical armature consisting of one proximal stout and short spine and distally with one pinnate spine and one large geniculate seta; apical armature consisting of five setae: one inner pinnate spine and four geniculate setae. 


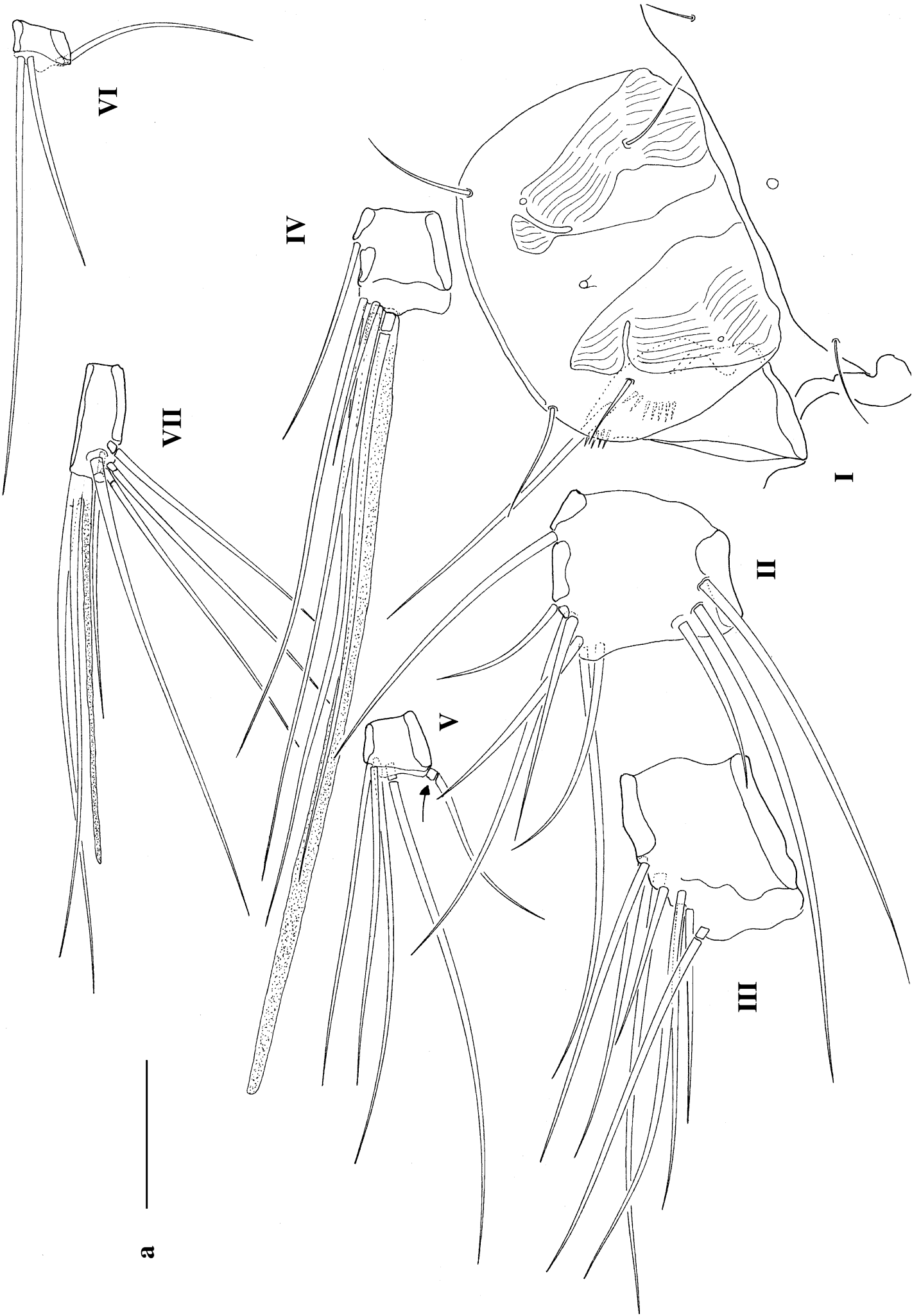

Fig. 3 Xylora calyptogenae gen. n., spec. n., female holotype. Antennule and rostrum, $a$ scale bar $=20 \mu \mathrm{m}$

Mandible (Figs. 6, 7). Gnathobase with few large pointed teeth, outer edge with strong multipinnate seta of rigid appearance; basis with four setae; enp with three lateral and five basally fused terminal setae, exp with a row of three large spinules and four setae altogether, 1 lateral one being enlarged and pinnate tapering into a flexible tip and three terminal pinnate setae. 
Maxillule (Fig. 8). Arthrite of praecoxa with eight apical spines and two juxtaposed setae on anterior surface, the four innermost apical spines displaced, both posterior spines stout and strongly sclerotized, anterior ones more slender; coxa demarcated from basis, coxal endite at least with five setae; basis bearing $3+2$ setae; enp fused with basis, oriented parallel to basis and bearing three setae, exp short, with two long setae.

Maxilla (Fig. 4). Syncoxa with spinules and three endites; proximal endite bilobed, proximal lobe shorter bearing one pinnate spine, distal lobe with long pinnate seta and one smaller pinnate spine, middle endite with two smooth and slender setae, distal endite with one pinnate spine-like flagellate seta and anteriorly one smooth and slender seta; basal endite with one claw, not demarcated and armed in distal half with three large spinules, posterior side of basis with one slender smooth seta, anterior side with proximal geniculate claw and distal slender smooth seta; enp uni-segmented bearing four setae.

Maxilliped (Fig. 5). Syncoxa approximately half as long as basis, with one long pinnate seta at distal margin and spinule patches at proximal inner and distal edge; basis smooth, bearing one short plumose setae on inner margin; enp fused with large endopodal claw and bearing one anterior small seta.

P1 (Fig. 4). "Prehensile". Coxa with several spinule rows on theanterior surface. Basis with pinnate outer and pinnate inner spine both of which accompanied by basal spinule row. Exp three-segmented, outer margins fringed with spinules; exp1 and exp2 each with one long and slender outer pinnate spine, inner margins asetose; exp3 with three slender outer pinnate spines, terminally with one outer slender spine and one inner long, geniculate seta; enp two-segmented; enp1 extremely elongated, being far longer than exp, with spinule rows along inner margin and on the anterior and posterior surfaces, bearing one serrate inner seta inserting in distal half; enp2 very short, with three setae in total all of which located terminally: one anterior strong, curved and smooth claw, one middle smaller pinnate claw and one posterior minute seta, outer margin of enp2 armed with 1-2 elongated spinules.

P2-P4 (Figs. 5, 6, 7). Exps and enps three-segmented. Coxae of almost rectangular shape, tapering towards inner margin, with few spinule rows each. Basis with long, smooth and slender outer seta (except the one in P2 being enlarged and pinnate) with basal spinule row. P2 and P3 enps three-segmented, P4enp two-segmented, all segments fringed with spinules along the outer and distal margins. Endopodal setae of quite individual shape, inner setae on P2 enp2, P3 enp2 and P4 exp2 enlarged and serrate, middle terminal seta on P2 enp3 minute. P2 enp3 outer terminal seta miniaturised. For setal formula see Table 1.

P5 (Fig. 8). Pair of legs separated, endopodal lobe not quite prominent with four setae, second innermost of which is shortened, serrate and strong; exp small, broader than long with one inner, two terminal and one outer seta, all setae pinnate. Spinule rows present on terminal margin and basally of the exp insertion consisting of longer spinules, insertion point of basal outer seta very low, hidden behind posterior side of exp.

Male: unknown

\section{Discussion}

\section{Systematics}

A closer relationship of the Donsiellinae Lang, 1944 with the Pseudotachidiidae Lang, 1936 was already stated by Hicks (1988). They can be assigned to the latter taxon on the basis of the following combination of characters (compare Willen 1999, 2000; condition present in the basic pattern of Oligorarthra in brackets):

- antennular segments $4+5$ (the numbering refers to the nine-segmented female antennule in the Harpacticoida Oligoarthra basic pattern) not separated (these segments separate in Oligoarthra basic pattern),

- A2 exp3 with only two apical setae (three setae),

- Mxl coxal outer seta missing (present),

- Mxl enp with only three setae (four setae),

- Mxp as described in Willen (2000, pp. 128, 132, Fig. 49),

- shape of P5: exp small, benp with innermost seta elongate and second innermost seta shortened (compare Fig. 8) (innermost and second innermost setae quite short and of equal length and shape),

- anal somite completely divided (compare Figs. 1,2) (not divided),

- caudal seta I missing (present and well developed), male P2 enp3 with sexual dimorphic modified seta (setae unmodified), male P3 enp2 with sexual dimorphic segmental process (without process).

Within the Pseudotachidiidae the Donsiellinae can be well characterised by numerous autapomorphies, e.g., the outermost apical geniculate seta of A2 enp without accompanying fused seta, A2 exp two-segmented, Mxl exp with only two setae, P1 enp1 extremely elongated, enp2 very small with two terminal claws, all swimming leg exopods lacking setation on inner margin, except for P4 exp3 bearing a single enlarged serrate inner seta, P3 and P4 exp3 each with only four spines and setae in total, P4 enp at most two-segmented, single swimming leg enp setae of the basic pattern formula missing: P2 enp1, enp2 and enp3 inner seta, P3 enp 3 inner setae, P4 enp inner setae on terminal segment (former enp2 +3 ), female P5 exp flattened with only four setae, benp with only four setae, male P2 with characteristic sexual dimorphism (compare descriptions of Hicks 1988): enp always three-segmented, terminal seta modified, fused to segment in the more derived condition, baseoendopod and exp of male P5 fused.

The Donsiellinae share some apomorphies with the pseudotachidiid subtaxon Paranannopinae Por, 1986: 


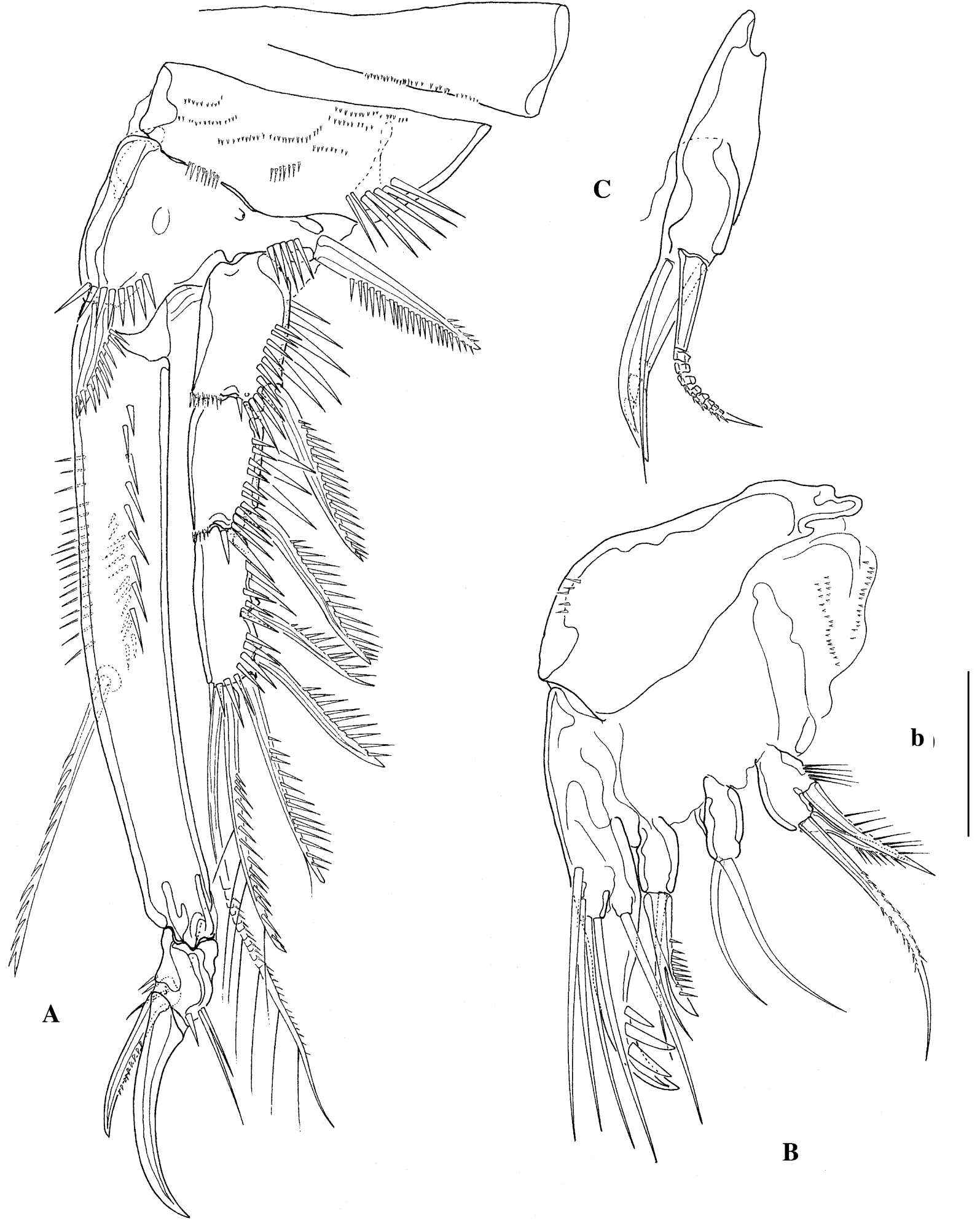
maxillar basis in anterior view 


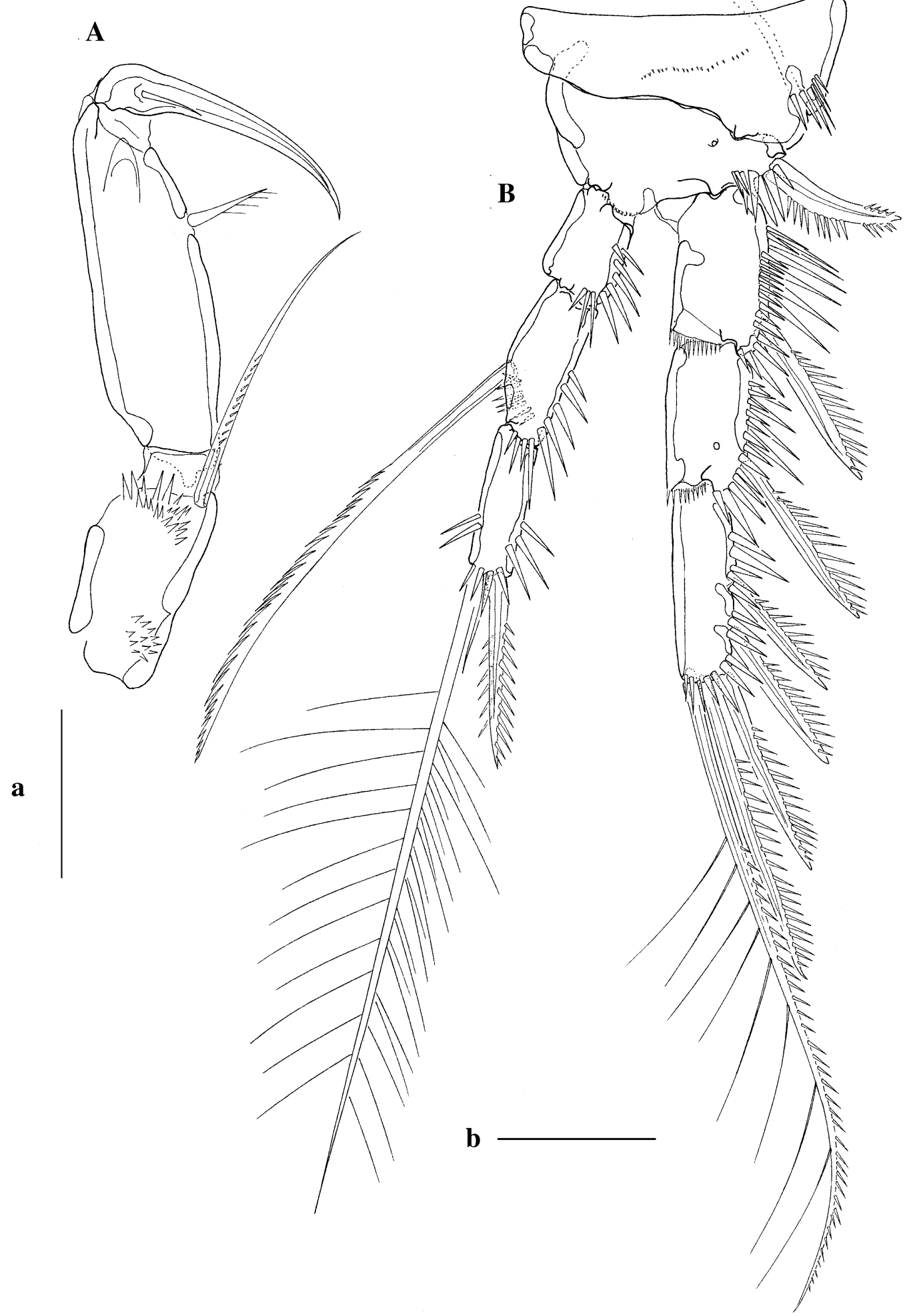

Fig. 5 Xylora calyptogenae gen. n., spec. n., female holotype. $A$ Maxilliped, $a$ scale bar $=20 \mu \mathrm{m} ; B$ Peraeopod $2, b$ scale bar $=30 \mu \mathrm{m}$ 


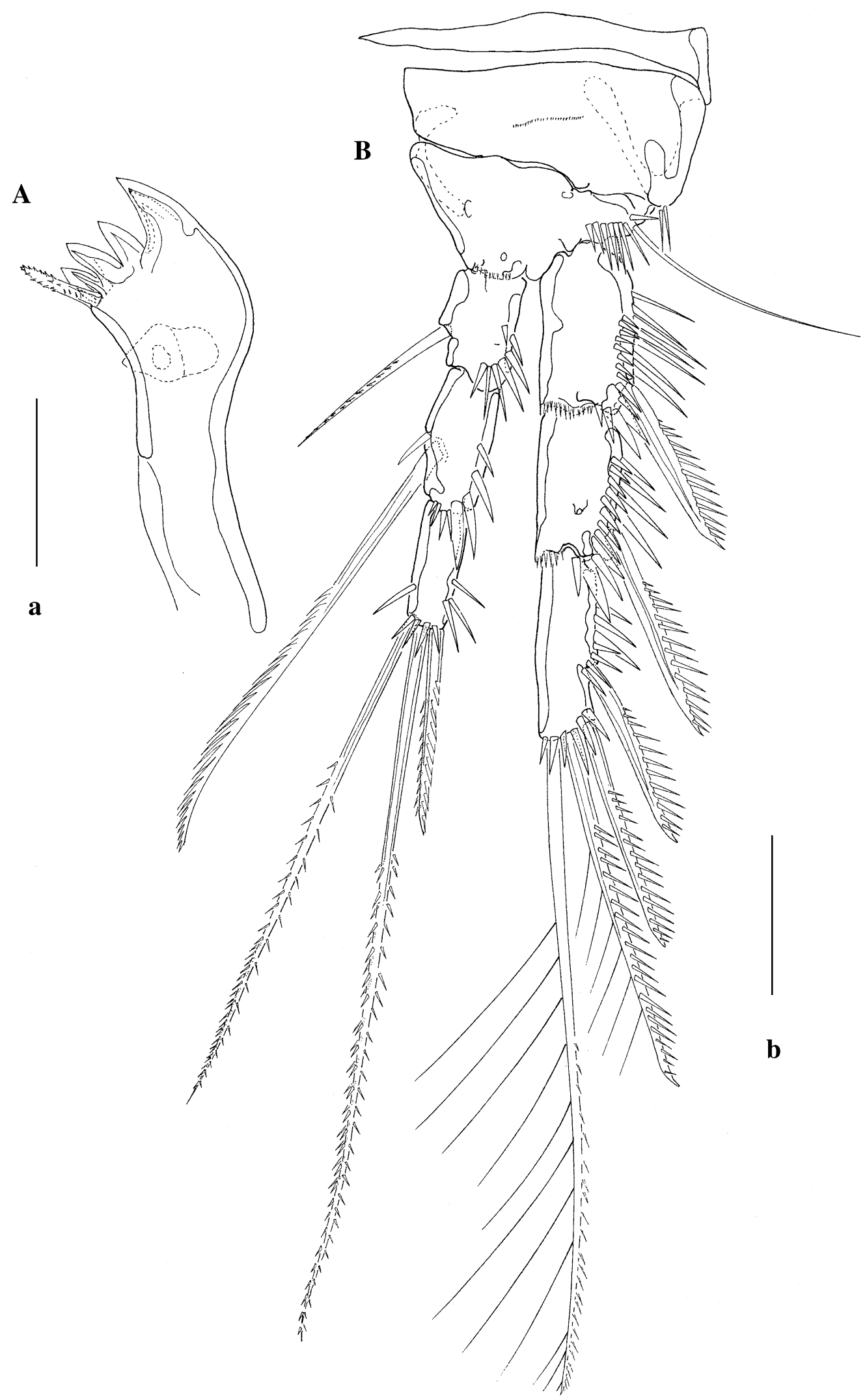

Fig. 6 Xylora calyptogenae gen. n., spec. n., female holotype. $A$ Mandible gnathobase, $a$ scale bar $=20 \mu \mathrm{m} ; B$ Peraeopod 3, $b$ scale bar $=30 \mu \mathrm{m}$ 


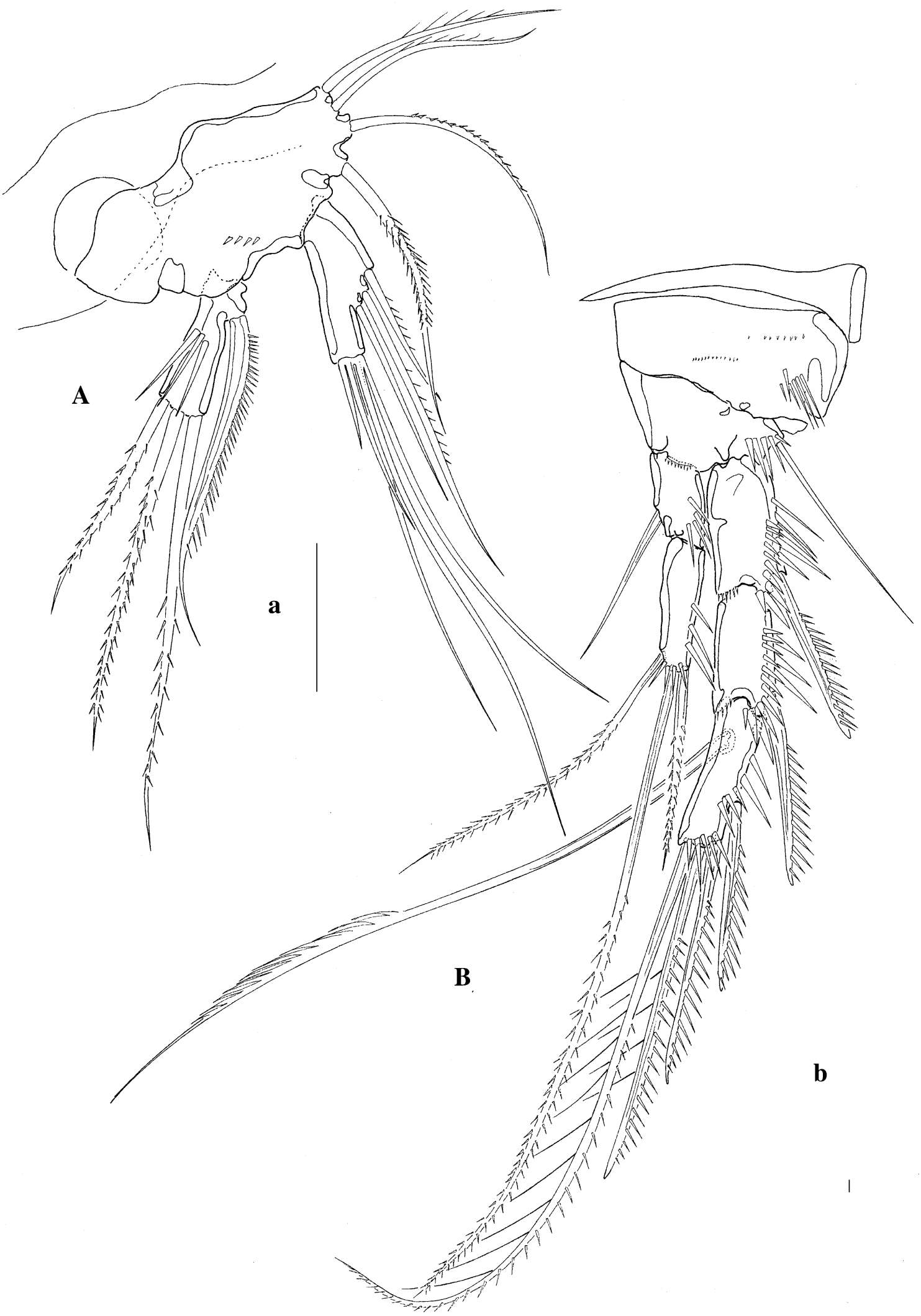

Fig. 7 Xylora calyptogenae gen. n., spec. n., female holotype. $A$ Mandible palp, $a$ scale bar $=20 \mu \mathrm{m} ; B$ Peraeopod $4, b$ scale bar $=30 \mu \mathrm{m}$ 
Table 1 Setal formula of swimming legs (after Lang 1948)

\begin{tabular}{lll}
\hline & Exp & Enp \\
\hline P2 & $0-0-0,2,3$ & $0-1-0,2,1$ \\
P3 & $0-0-0,2,2$ & $1-1-0,2,1$ \\
P4 & $0-0-1,2,2$ & $1-1,1,1$ \\
\hline
\end{tabular}

- Mx enp uni-segmented with only 4 setae arranged as shown in Willen (2000b, p. 118, Fig. 39),

- Mx precoxal endite derived from pseudotachidiid basic pattern by lacking one seta on the distal lobe (see Willen 2000, p. 123, Fig. 44),

- P1 enp two-segmented, enp2 without inner seta (one inner seta of the former P1enp3 is missing in the Paranannopinae and Donsiellinae but still present in other representatives of the Pseudotachidiidae such as e.g., Pseudotachidius coronatus, compare Willen 2000, p.144, Fig. 55),

- female A1 segment 4 in Fig. 3 with only 6 setae + aesthetasc $(6+2$ setae + aesthetasc in pseudotachidiid basic pattern, compare Willen 2000, p. 64).

Hicks (1988) proposed a phylogenetic scheme of the Donsiellinae splitting them up into two groups, placing Donsiella Stephensen, 1936, Apodonsiella Hicks, 1988 and Pseudonsiella Hicks, 1988 together as the more advanced lineage. Confirming this, the latter group can be characterised by e.g., the following apomorphies compared to the basic pattern of the Donsiellinae which is to a large extent represented by Xylora, Hicks, 1988/Oligoxylora, (Hicks, 1988) (see descriptions of Hicks 1988): the outermost geniculate apical seta on A2 enp is shortened and thickened, the outermost apical seta on A2 exp is naked, flexible and slender compared to the remaining A2 exp setation, Mxp without basal and endopodal seta, P1 with short exp not reaching the first half of the enp, enp1 without inner seta, exp3 with only four setae, female P2 with only two-segmented enp (the female of Apodonsiella is yet unknown), exp3 with only four setae (five in Xylora and Oligoxylora), basal outer seta long and slender (spine-shaped in Xylora and Oligoxylora and other Oligoarthra), P3 enp1 without seta, P4 enp at most one-segmented with maximal two terminal setae, male P3 enp3 characteristically modified (unmodified in Xylora and Oligoxylora). In each of these aspects the remaining genera Xylora and Oligoxylora show the respective plesiomorphic state. The characterisation of Xylora and the "lineage" comprising Xylora and Oligoxylora by Hicks is mainly based on plesiomorphies. However, the sevensegmented female antennule shared by these taxa considered to be "primitive" at first sight could rather turn out to be an apomorphic feature: At first the sevensegmented condition appears to be the most primitive state to be present within the Donsiellinae which show principally the same segmentation and setation as the Paranannopinae. In the basic pattern of the latter, the female antennule is six-segmented and the segments 6-8 of the nine-segmented "ancestral" oligoarthran antennule are not separated but form a single compound segment (compare Willen 2000,p. 64). In Xylora (in Oligoxylora the antennular setation has not been described) - as the only representative within the Donsiellinae and Paranannopinae - the segments $7+8$ of the original nine-segmented Oligoarthra antennule (forming the actual segment six in Fig. 3) are separated from this compound segment. Segments $7+8$ can always be identified by carrying one anterior and one articulated posterior seta each in the Oligoarthra basic pattern. By bearing the articulated posterior setae these segments can even be readily identified and homologised within the different copepod orders (compare Huys and Boxshall 1991). In Xylora, the small segment six in Fig. 3 representing segments $7+8$ of the Oligoarthra basic pattern carries only three setae, lacking one of the posterior articulated seta which is actually located in the precedent segment (arrow marked in Fig. 3). This peculiarity is present in all available specimens of Xylora and speaks more in favour of a secondary separation of segment six from the preceding segment (Fig. 3), which in a more ancestral state would have also included these segments according to the paranannopid and donsiellinid basic pattern. Thus this antennular character is interpreted here as a further autapomorphy of Xylora, probably also including Oligoxylora - rather than as a primary phenomenon.

Furthermore, the species of Xylora shares the two modified spines on the maxillule precoxa, the modification being much more pronounced and the spines displaced in X. bathyalis Hicks 1988, and X. calyptogenae spec. n. compared to X. neritica Hicks, 1988. On the other hand, the former two species of Xylora share with Oligoxylora cooksoni Hicks, 1988 a one-segmented Md exp with only one lateral and three apical setae, the inner seta of P1 enp1 inserting medial/in distal half and the flattened shape of the female P5 benp. The antennular setation and the maxillule of $O$. cooksoni have not been described by Hicks. Therefore a relationship between all these taxa seems to be probable but has to be established in detail by additional data.

$X$. calyptogenae spec. $\mathrm{n}$. is most closely related to Xylora bathyalis Hicks (1988), which is "frequently the dominant harpacticoid copepod on deep sea wood substrata in New Zealand waters" (Hicks 1988, p. 683). Morphological differences (according to the description of Hicks 1988) can be found in the lateral seta of Md exp, being modified in X. calyptogenae spec. n./unmodified in $X$. bathyalis, Mxl enp well developed and distinct if not demarcated/"rudimentary" with short spinulose outer seta, small seta on Mxp enp present/absent, P1enp1 inner seta serrate/not serrate, inner setae on P2 and P3 enp2 strongly serrate/not serrate, female genital field of different shape (compare Fig. 2 with Fig. 18e in Hicks 1988, p. 665), female P6 with $3 / 2$ setae, female P5 with hyaline field at inner margin/without hyaline field. 


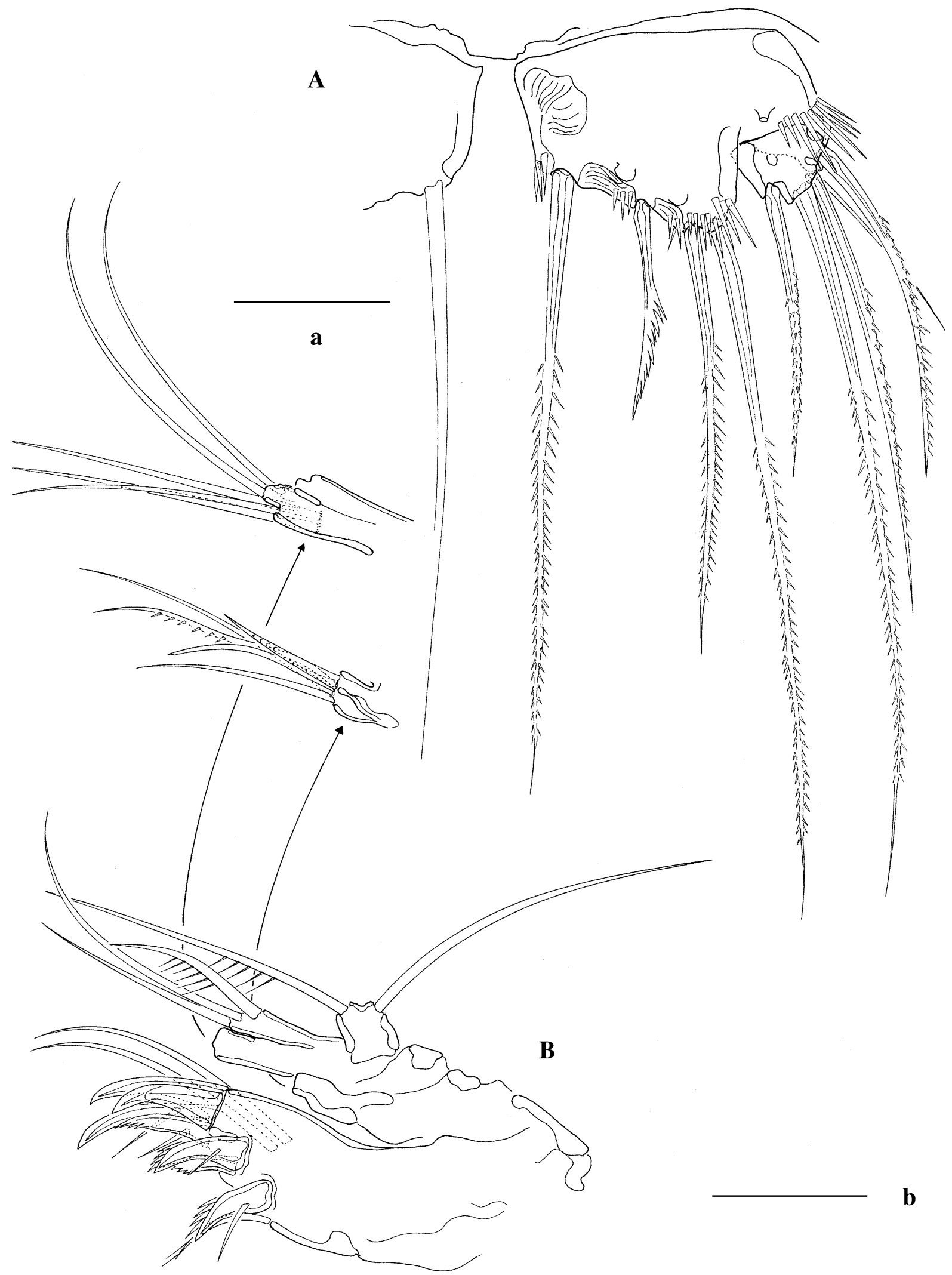

Fig. 8 Xylora calyptogenae gen. n., spec. n., female holotype. $A$ Peraeopod $5, a$ scale bar $=30 \mu \mathrm{m} ; B$ Maxillule, $b$ scale bar $=20 \mu \mathrm{m}$ 
Ecological considerations

The occurrence of a member of Donsiellinae in a hydrothermal environment is quite surprising. Up to now, species of this taxon have been encountered exclusively in association with water-logged, decaying and in most cases teredinid and/or gribble-bored wood. Hicks (1988) published a revision of the Donsiellinae with the description of numerous new taxa from the Australasian region and summarised some ecological data. The advanced donsiellinid taxa Donsiella, Apodonsiella, Pseudonsiella and also Xylora neritica and Oligoxylora have been found in shallower waters and always in association with the species of the wood-boring isopod Limnoria (Leach, 1814).

Some species, such as Donsiella victoriae Hicks, 1988 and D. limnoriae Stephensen, 1936 have even been reported to cling firmly to the body of the isopod using the first swimming leg, suggesting at least a commensal relationship between copepod and Limnoria. The closest relative of $X$. calyptogenae spec. n., $X$. bathyalis, replaces the other donsiellinid species in greater depths up to $1500 \mathrm{~m}$. Still found in decaying bored wood, it is not always associated with Limnoria. The species of the latter which have been reported yet together with donsiellinids, are not adapted at all to the colder temperatures occurring in the deep sea (Kühne and Becker 1964). An "evolutionary history" of the Donsiellinae can be outlined, starting from the more primitive deep sea taxa $X$. calyptogenae spec. $\mathrm{n}$. which lives in the hydrothermal seafloor in the absence of decaying wood, and $X$. bathyalis, which is found on decaying wood (but not searched for on the bottom?) but not necessarily associated with Limnoria, to the also morphologically more advanced genera such as Donsiella, which invades shallow waters and, as a further step, clings to the woodboring isopod Limnoria itself in a close and, for the copepod, probably obligatory association (Hicks 1988; Pinkster 1968).

Several different harpacticoid species have already been encountered in bored wood, most of them well known from other habitats as well and therefore not specialised, e.g., the widely distributed and "normally" algae dwelling Tisbe gracilis (Scott, 1895) (Pinkster 1968; Boer 1971; Barnard and Reish 1960). In any case, decaying wood supplies a possible food source for harpacticoids, even without particular specialisation to use it. The Donsiellinae, however, seem to be well adapted to a specialised life-style, showing reduced swimming ability and a distinct substrate dependence. The P1 with its "grappling-hook" structure and the reduced swimming leg setation and segmentation is already present in the more primitive donsiellinid $X$. calyptogenae spec. $\mathrm{n}$. Its congener Xylora bathyalis, displaying nearly the same morphology, was encountered clinging to decaying wood. It is not clear, what kind of substrate would be equivalent at the hydrothermal site at Edison seamount. The samples taken from station 33 contained mainly macrofauna such as large vesicomyid clams and lepa- domorphs (Neolepas Newman, 1979) while the sediment was coarse but homogenous. Therefore, an association with this or other macrofauna would be a probable option. However, since X. calyptogenae spec. n. is supposed to be carnivorous (see below), this kind of association would presumably not involve commensal dependence.

Both habitats, pieces of decaying wood and hydrothermal vents, show principally temporal instability and sporadic occurrence, factors to which the species of Donsiellinae seem to be well adapted. Pinkster (1968) conducted some experiments to assess the relationships between Donsiella limnoriae Stephensen, 1936 and Limnoria tripunctata Menzies, 1951 and observed that while all adult copepods were clinging to the body of the isopod and die quickly without this association, the nauplii were free-swimming and therefore potentially able to migrate.

Feeding behaviour and mouthpart morphology in $X$. calyptogenae spec. $n$.

Considering a generalised scheme of trophic interactions in a vent ecosystem (compare Van Dover 2000), the possible "roles" taken over by meiobenthic copepods could be those of grazers, detritivores, scavengers and predators. An important food source for copepods at vents seems to be the free-living bacteria occurring as microbial mats, suspended in the water body, in flocs, as debris settled on the seafloor or on the bodies of other invertebrates such as crabs and limpets. Humes and Lutz (1994) observed large amounts of copepods on the carapace of Bythograea thermydron Williams, 1980, on the shells of Lepetodrilus elevatus McLean, 1988 and on other bacteria-covered organic and inorganic surfaces in the vicinity of active hydrothermal flow, and they collected Aphotopontius acanthinus Humes and Lutz, 1994 (Siphonostomatoida, Dirivultidae) from a bacteria-covered chimney from a deep sea vent site on the East Pacific Rise. Bacteria, the only source of primary production, are certainly a major food source for vent harpacticoids also. Another possible feeding strategy is scavenging, perhaps also of larger organisms (e.g. fish), which has actually been observed in cultured Ectinosoma carnivora Seifried and Dürbaum 2000 and E. melaniceps Boeck, 1864 by Seifried and Dürbaum (2000). A species of Pseudobradya Sars, 1904 with a similar general morphology as the latter two species has also been encountered with several individuals at Edison Seamount. Generally, Ectinosomatidae are distributed worldwide, in all kinds of habitats including the deep sea, and are therefore not characteristic of vent sites.

The specialised mouthpart morphology of X. calyptogenae spec. $n$. also suggests a different food strategy than grazing of bacteria. In the gut of 1 paratype specimen of $X$. calyptogenae spec. n., the partly digested remains of a larger animal have been detected which was identified by light microscopy as another copepod. This 
confirms the assumption of a carnivorous feeding mode. Mouthpart specialisations include (1) a mandible gnathobase with only a few large teeth, (2) the gnathobasal seta being stout, comparably unflexible, multipinnate and armed with tiny spinules, (3) a small labrum forming a "roof" being completely covered with spinules from underneath like an inverted pin-cushion, (4) a Mxl with the innermost posterior precoxal spines being displaced proximally, strongly sclerotised and armed with spinules while the precoxal arthrite itself is slightly tapering and apically armed with claw shaped spines, (5) a maxillar basal claw, bearing 3 large spinules near the tip and the proximal anterior accompanying seta being thoroughly geniculate.

Only very few data are available on the predatory behaviour of harpacticoid copepods in general. The deep sea genus Parameiropsis (Becker, 1974) is suspected to be predatory because of its aberrant mouthpart morphology. In all the three species (compare the descriptions in Becker, 1974; and Itô, 1983), P. rapiens Becker, 1974, P. peruanus Becker, 1974 and P. magnus Itô, 1983, the mandible is extremely slender and stiletto-like, the gnathobasal teeth are elongated and thin, the elongated gnathobase seta is situated on a tooth-like projection. The maxillule is very slender, its precoxa arthrite apical spines are seta-like, the maxillar syncoxal endites are reduced in size and number whereas the basal claw is very well developed with serrated inner margin, the maxillipedal claw is also serrated. Tisbe furcata (Baird, 1837), which has been observed to be carnivorous (Marcotte 1977), shows a comparable functional shape of the mouthparts (compare Dahms et al. 1991) though there are also differences. In X. calyptogenae spec. n. the modifications have taken a different direction. The shape of the mandible gnathobase is not so extremely modified, the teeth are large but not remarkably elongated, the gnathobase seta is short, not elongate, the maxillule precoxa is only slightly tapering, the precoxal spines are not seta-like but strong and claw-like, the syncoxal maxillar endites are still comparably well developed and the basal claw is not serrated but bears three large spinules and is accompanied by a strong, thoroughly geniculate seta.

Marcotte (1977) observed and described in detail the raptorial feeding behaviour of the harpacticoid Tisbe furcata which grasps food rather than "filter" it from the water. The highly mobile and dextrous maxilla is the main appendage to grab and also impale food particles by using the basal claw and manipulate them to the mouth. Mandible and maxillule are inactive when first encountering the food particle. The antenna is important to hold particles within the hypopharyngeal complex. The Mxp is not involved in the initial step of food capture (at least in the case of small diatoms and detritus which were used as food in the study) but supports the maxilla in pushing the food to the mouth and guarding the posterior and ventral margins of the hypopharyngeal complex. When the food particle is orientated with its long axis parallel to the main axis of the copepod, the mandible and maxillule take over the food ingestion process by crushing the food item (mandible) and propelling it into the mouth. A study of the feeding structures and their functions in Tigriopus californicus (Baker, 1912) was carried out by Lewis et al. (1998). This species is a generalist, showing no specialised "raptorial" morphology and using a variety of food types, including prey organisms found in splashpools. Different food types are handled by different mouthpart functions. Prey (e.g. small crustaceans) acquisition is carried out by the maxilliped and possibly the first leg, fixation to the hypopharyngeal complex by the teeth and claws of labrum and labium. The holding capability is increased by the spreading of the paragnaths and rotating of the "labial claws". Pieces of prey are bitten off while the food item is held by the appendages. Breakup and transfer to the oesophagus is done by the teeth and spinous setae of the opposing gnathobases. Compared to the generalist $T$. californicus, $X$. calyptogenae spec. $\mathrm{n}$. shows a more specialised mouthpart morphology. The maxillar claw, armed with the three large spinules and a strong geniculate claw-like seta, seems to be constructed not so much to impale objects as observed in Tisbe furcata, but to grab an active or larger object and to hold and fix it within the hypopharyngeal complex. This is supported by the maxillular precoxal arthrite being armed with the posteriorly directed spinous, sclerotised and apparently mobile spines, and by the claw-like and pointed apical spines (see Fig. 9). The gnathobase of the mandible has 1 large distal multicuspid tooth which could hold onto a larger object in the hypopharyngeal complex, assisted by the small "pin-cushion" labrum and only a few more large teeth. Once beneath the labrum, a food object is prevented from escaping by the labral spinules which are directed towards the mouth. The general shape of the mandible gnathobase reminds of the mandible of carnivorous ectinosomatids (compare Seifried and Dürbaum 2000) rather than the mandibles of Tigriopus californicus (compare Lewis et al. 1998) or of diatom and bacteria consuming species Amphiascoides Nicholls, 1941, which show numerous smaller, pointed teeth besides 2 larger bi- or multicuspid ones. It is also possible that the hooklike P1 is involved in food acquisition as it has been observed in T. californicus (see above). Another possible prey for $X$. calyptogenae spec. n. besides other copepods could be nematodes which are available in all sizes at the type locality. Predation on nematodes by a harpacticoid copepod was observed by Lehman and Reid (1992). Phyllognathopus viguieri (Maupas, 1892) and P. affinis (according to Reversat et al. 1992 in Lehman and Reid 1992) are capable of consuming considerable numbers of nematodes per day and probably have a strong impact on nematode population in moist soils, at least in the case of $P$. viguieri. However, the authors discuss that predation of nematodes is not necessarily evident from copepod mouthpart morphology and thus may be far more widespread than thought before. Apparently, mouthpart morphology does not seem to determine exactly the kind of food 


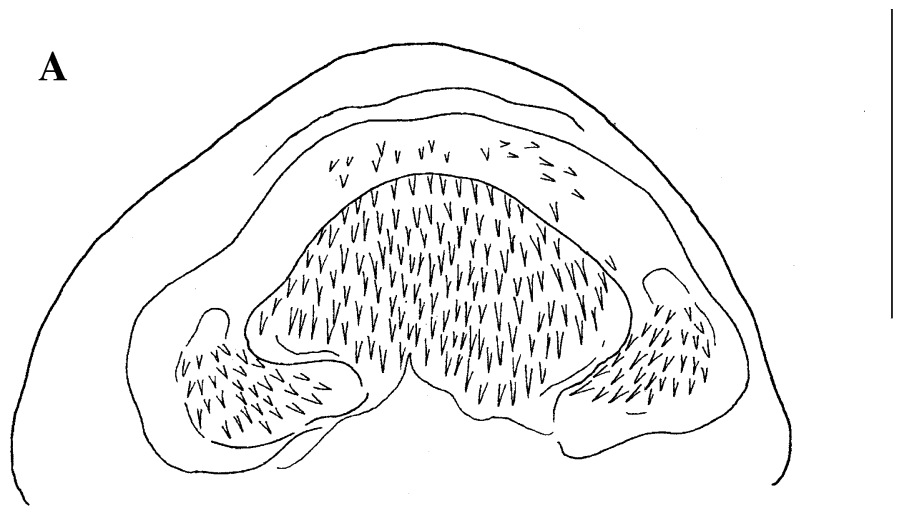

a

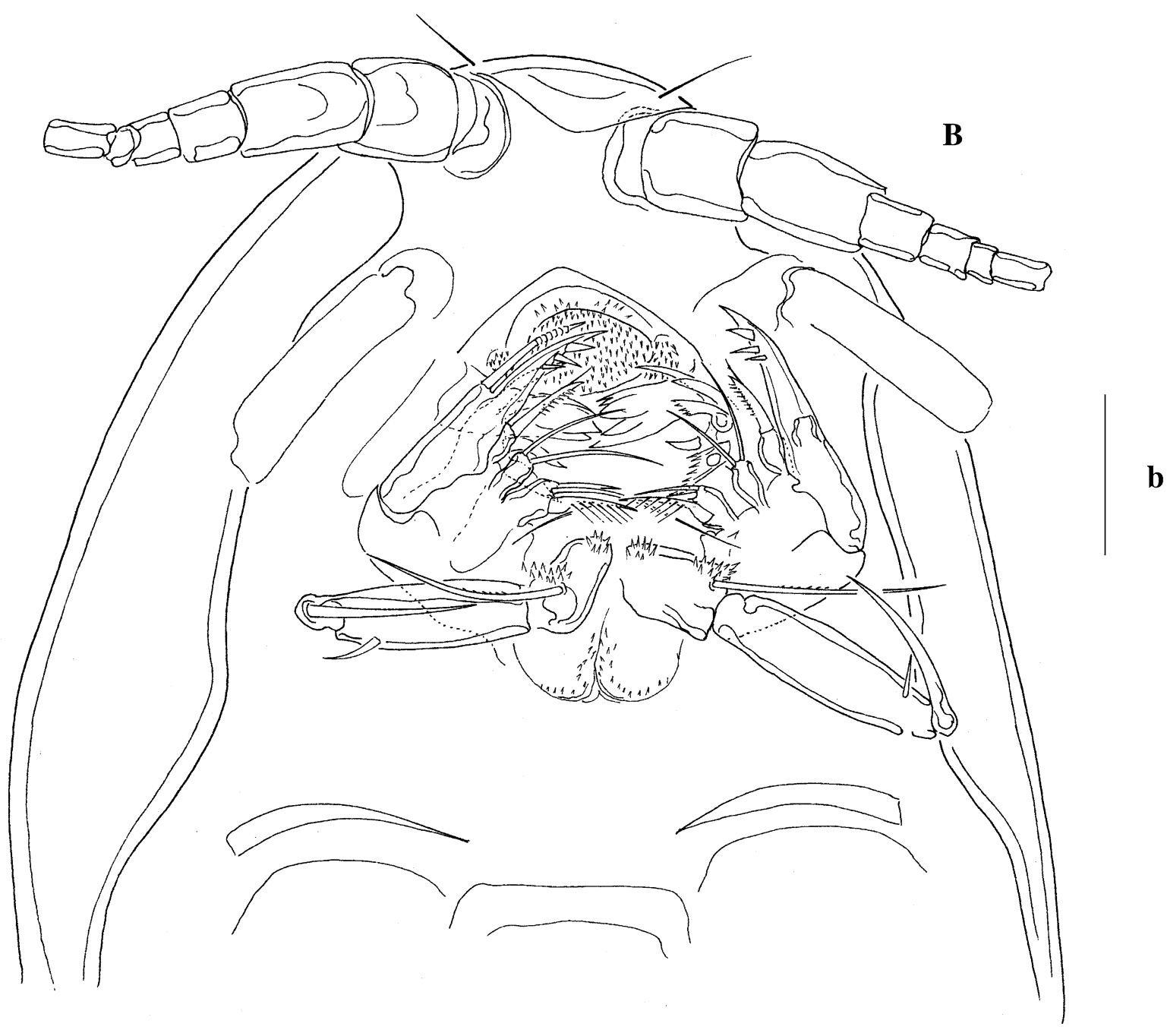

Fig. 9 Xylora calyptogenae gen. n., spec. n., female holotype. $A$ Labrum in situ in ventral view, $a$ scale bar $=20 \mu \mathrm{m}$; $B$ Cephalothorax from ventral view, $b$ scale bar $=30 \mu \mathrm{m}$

which can be consumed. Tisbe furcata e.g., has been cultured on various types of food, including large detritus particles, nematodes, algae Dunaliella (Teodoresco, 1905), meat of Mytilus edulis (Linnaeus, 1758) and artificial food (Marcotte 1977; Dahms et al. 1991). On the other hand T. californicus preys on other copepods without showing a specialised "raptorial" morphology (Lewis et al. 1998). Each species is probably 
adapted to those food sources which are most favourable for its maintenance and reproduction in the field (compare Hicks and Coull 1983).

Acknowledgments Thanks are due to Prof. H. K. Schminke for general support and critical comments on the manuscript. The author was funded by the Forschungsinstitut und Naturmuseum Senckenberg, Frankfurt. Dr. M. Türkay and Dr. J. Stecher made the samples of the SONNE cruise 133 available.

\section{References}

Ax P (1984) Das phylogenetische system. Gustav Fischer Verlag, Stuttgart

Barnard JL, Reish DJ (1960) Wood-browsing habits of the harpacticoid copepod Tisbe gracilis (T. Scott) in Southern California. Pacific Naturalist 1/22:9-12

Becker KH (1974) Eidonomie und Taxonomie abyssaler Harpacticoidea (Crustacea, Copepoda).Teil I. Cerviniidae - Ameiridae. "Meteor" Forsch Erg 18:1-28

Boer P (1971) Harpacticid copepods (Crustacea) living in wood infested by Limnoria from northwestern France. Bull Zool Mus Univ Amsterdam 2/8:63-72

Dahms HU, Schminke HK, Pottek M (1991) A redescription of Tisbe furcata (Baird, 1837) (Copepoda, Harpacticoida) and its phylogenetic relationships within the taxon Tisbe. Z Syst Evol 29:433-449

Itô T (1983) Harpacticoid copepods from the Pacific abyssal off Mindanao. II. Cerviniidae (cont.), Thalestridae, and Ameiridae. Publ Seto Mar Biol Lab 28(1/4):151-254

Hicks GFR (1988) Systematics of Donsiellinae Lang (Copepoda, Harpacticoida). J Nat Hist 22:639-684

Hicks GFR, Coull BC (1983). The ecology of marine meiobenthic harpacticoid copepods. Mar Biol Ann Rev 21:67-175
Huys R, Boxshall GA (1991) Copepod evolution. The Ray Society, London

Humes AG, Lutz RA (1994) Aphotopontius acanthinus, new species (Copepoda: Siphonostomatoida), from deep-sea hydrothermal vents on the east Pacific rise. J Crust Biol 14:337-345

Lang K (1948) Monographie der Harpacticiden I + II. Håkan Ohlssons Boktryckeri, Lund

Lang K (1965) Copepoda Harpacticoidea from the Californian Pacific coast. K Svenska vetens akad Handl 10/2:1-566

Lehman PS, Reid JW (1992) Phyllognathopus viguieri (Crustacea: Harpacticoida), a predaceous copepod of phytoparasitic, entomopathogenic and free-living nematodes. Soil and Crop Science Society of Florida, Proceedings 52:78-82

Lewis AG, Chatters L, Raudsepp M (1998) Feeding structures and their functions in adult and preadult Tigriopus californicus (Copepoda, Harpacticoida). J Mar Biol Assoc UK 78:451-466

Marcotte BM (1977) An introduction to the architecture and kinematics of Harpacticoid (Copepoda) feeding: Tisbe furcata (Baird, 1837). Mikrofauna Meeresboden 61:183-196

Pinkster S (1968) Harpacticoid copepods living in wood infested by Limnoria from France. Bull Zool Mus Univ Amsterdam 1/ 6:53-65

Seifried S, Dürbaum J (2000). First clear case of carnivory in marine Copepoda Harpacticoida. J Nat Hist 34:1595-1618

Tunnicliffe V, McArthur AG, McHugh D (1998) A biogeographical perspective of the deep-sea hydrothermal vent fauna. Adv Mar Biol 34:354-441

Van Dover C (2000) The ecology of deep-sea hydrothermal vents. Princeton University Press, Princeton

Vanreusel A, Van den Bossche I, Thiermann F (1997) Free living nematodes from hydrothermal sediments: similarities with communities from diverse reduced habitats. Mar Ecol Progr Ser 157:207-219

Willen E (1999) Preliminary revision of the Pseudotachidiidae. Cour Forsch Inst Senckenberg 215:221-225

Willen E (2000) Phylogeny of the Thalestridimorpha 1944 (Crustacea, Copepoda). Cuvillier Verlag, Göttingen 